\title{
Avaliação Isocinética em Jogadores de Futebol Profissional e Comparação do Desempenho Entre as Diferentes Posições Ocupadas no Campo
}

\section{Isokinetic Assessment in Professional Soccer Players and Performance Comparison According to Their Different Positions in the Field}

Fernanda Seganfredo Weber ${ }^{1}$ Bruna Gonçalves Cordeiro da Silva Régis Radaelli

Cláudio Paiva

Ronei Silveira Pinto

1. Laboratório de Pesquisa do Exercício, Universidade Federal do Rio Grande do Sul, Brasil.

Endereço para correspondência: Ronei Silveira Pinto, Escola de Educação Física da UFRGS, Laboratório de Pesquisa do Exercício (Lapex), Rua Felizardo, 750 90690-200 - Porto Alegre, RS - Brasil E-mail: feweber@terra.com.br ronei.pinto@ufrgs.br

\begin{abstract}
RESUMO
O objetivo geral deste estudo foi o de analisar os dados de pico de torque (PT) e índice de fadiga coletados em testes isocinéticos de atacantes (A), meias (M) e defesas (D), a fim de traçar um perfil destes atletas. A amostra foi constituída de 27 jogadores profissionais de futebol com média de idade de 26,55 \pm 5,1 anos, divididos nos grupos A (seis), M (sete) e D (14). Os atletas foram submetidos a teste isocinético com cinco repetições máximas de flexão (concêntrica e excêntrica) e extensão (concêntrica) do joelho na velocidade de $60 \%$ s e 30 repetições máximas de flexão e extensão (concêntricas) do joelho na velocidade de $300^{\circ} / \mathrm{s}$. A partir dos dados coletados, foi observado que o grupo D apresentou valores significativamente mais elevados de PT concêntrico de flexores do lado dominante (LD) a 60\% em comparação ao M ( $p=0,05$ ). No entanto, para as demais variáveis de PT e índice de fadiga não foram encontradas diferenças entre as posições. Com relação ao déficit bilateral (DB), os atletas apresentaram valores dentro da normalidade. Quanto às razões, foi observado que os jogadores encontravam-se dentro dos valores normativos para razão convencional, porém estavam abaixo dos valores normais para a razão funcional. Conclui-se que, apesar de desempenharem funções diferentes dentro do campo, isso não parece influenciar decisivamente a maioria das características neuromusculares dos membros inferiores nos atletas de futebol avaliados.
\end{abstract}

Palavras-chave: futebol, funcional, razão convencional, fadiga e déficit bilateral.

\begin{abstract}
The aim of this study was to analyze the data collected from the peak torque (PT) and the fatigue index in isokinetic tests from forwards (F), midfielders (M) and defenders (D) in order to draw a profile of these athletes. Twenty-seven elite male soccer players (mean age 26.55 \pm 5.1 years) were tested, and divided in groups $F(6), M$ (7) and D (14). They were submitted to an isokinetic test with five maximal repetitions of knee flexion (concentric and eccentric) and extension (concentric) at $60 \%$ s and 30 maximal concentric repetitions (flexion and extension) at $300 \%$ s. The collected data evidenced that group D showed significantly higher values of concentric flexors PT at $60 \%$ s on the dominant side (DS) compared to M ( $p=0.05)$. However, for the other PT variables and fatigue index no differences were found between positions. Concerning bilateral deficit (BD), the athletes presented values within normality. Regarding ratios, it was observed that the players were within the normative values for conventional ratio, but were below the normal values for the functional ratio. We concluded that despite the different positions in the field the players have, this fact does not seem to dramatically influence on the majority of neuromuscular characteristics of lower limbs in the assessed soccer players.
\end{abstract}

Keywords: soccer, functional, conventional ratio, fatigue and bilateral deficit.

\section{INTRODUÇÃO}

Na prática do futebol os membros inferiores são muito solicitados para a realização de ações como: corridas, sprints, saltos, chutes e desarmes ${ }^{(1)}$. O músculo quadríceps femoral possui papel importante na execução dos saltos, chutes e passes, enquanto que os isquiotibiais controlam as atividades de corrida e estabilizam o joelho nas situações que envolvem mudanças de direção ou desarme do adversário. Ressalta-se que estes últimos atuam também no momento de passe de bola ou chute, a partir da contração excêntrica(2). Sendo assim, as habilidades específicas do futebol dependem da produção de força desses músculos ${ }^{(1,2)}$.
Alguns investigadores sugerem que níveis insuficientes de força, principalmente dos isquiotibiais, podem estar associados a um risco acrescido de lesão dos tecidos moles ${ }^{(3-6)}$. Por estas razões, a avaliação e o controle da força muscular assumem importância particular na monitorização dos efeitos dos programas de treino, bem como na prevenção de lesões ${ }^{(4)}$. A avaliação da força muscular especificamente realizada em dinamômetro isocinético vem sendo utilizada no diagnóstico de disfunções neuromus culares, na reabilitação, no treino e na investigação, como indicador da função e desempenho de certos grupos musculares, sendo a sua medição feita a partir do pico de torque $(\mathrm{PT})^{(7)}$. Os principais desequilíbrios avaliados 
são aqueles de PT entre o membro dominante e não dominante (déficit bilateral) e dos músculos antagonistas em relação aos agonistas( ${ }^{(2,8,9)}$.

Por muitos anos, os desequilíbrios musculares relacionados ao joelho vêm sendo avaliados a partir da razão convencional (PT concêntrico dos flexores/PT concêntrico dos extensores) e valores entre 0,5 e 0,7 são considerados dentro da normalidade ${ }^{(7)}$. O uso somente desta razão como indicadora de desequilíbrios apresenta limitações, pois a contração concêntrica dos isquiotibiais simultânea à contração concêntrica do quadríceps é uma situação que não ocorre durante a execução de movimentos funcionais. No movimento de chutar a bola, por exemplo, ocorre a contração concêntrica dos extensores do joelho e excêntrica dos flexores; desta forma, a comparação dos picos de torque durante os referidos tipos de contração, seria o mais indicado para a observação dos desequilíbrios na articulação do joelho em jogadores de futebol. Sendo assim, a chamada razão funcional (PT excêntrico dos flexores/PT concêntrico dos extensores) é atualmente utilizada para tal avaliação, e valores próximos de 1 são consideradas dentro da normalidade ${ }^{(3,4,10-12)}$.

Tem sido sugerido também que o PT, as razões e os déficits bilaterais podem estar relacionados com as exigências específicas dos diversos desportos. Deste modo, o padrão motor de determinada modalidade desportiva poderia influenciar o perfil funcional dos atletas ${ }^{(8)}$. A investigação de jogos desportivos como o futebol tem demonstrado que também as posições/funções dos jogadores contribuem para uma adaptação funcional específica ${ }^{(2,10)}$. No estudo de Carvalho e Cabri (2007) não foram encontradas diferenças bilaterais e de razão convencional entre os jogadores de futebol de diferentes posições, porém o PT apresentou algumas diferenças entre zagueiros, meias, atacantes e goleiros ${ }^{(2)}$. Já no estudo de Tourny-Chollet et al. (2000) foram encontradas algumas diferenças bilaterais entre a média do PT nos atacantes e meias e também algumas diferenças entre os demais jogadores com relação à média do PT, principalmente nos isquiotibiais ${ }^{(10)}$.

Há divergências entre os resultados dos poucos estudos que avaliaram de forma isocinética a produção de força dos músculos flexores e extensores do joelho, bem como o equilíbrio de força entre ambos, comparando atletas de futebol de diferentes posições. Ainda que estas diferenças possam estar associadas às características específicas dos atletas avaliados e às metodologias utilizadas nestes estudos, é possível que as diferentes funções desempenhadas no campo de jogo afetem decisivamente os valores das variáveis acima reportadas, fato que torna o tema inconclusivo. A identificação da ocorrência ou não de desequilíbrios musculares na articulação do joelho em atletas de futebol de diferentes posições, tendo-se como referência valores normativos apresentados na literatura, poderá servir de apoio à organização do treino muscular. Desta forma, esta pesquisa teve como objetivos: a comparação dos dados coletados de PT do lado dominante (LD) e separadamente do lado não dominante (LND) entre os jogadores que atuam nas diferentes funções dentro do campo, a comparação do índice de fadiga dos flexores e extensores de joelho em cada grupo e entre os diferentes grupos musculares, a verificação da ocorrência ou não de desequilíbrios utilizando percentuais de ponto de corte de déficit bilateral, razão convencional e funcional dos jogadores e definição do perfil neuromuscular destes atletas.

\section{MÉTODOS}

Foram avaliados 27 jogadores de futebol profissional do sexo masculino com idade entre 18 e 35 anos. As coletas foram realizadas entre outubro de 2008 e fevereiro de 2009.

Os atletas compareceram ao Laboratório de Pesquisa do Exercício da UFRGS para realizar testes isocinéticos solicitados pelos clubes em que atuam. Previamente, os atletas assinaram o Termo de Consentimento Livre e Esclarecido, no qual apresentavam a sua concordância com a realização dos testes e liberação dos dados coletados para utilização de investigação no presente estudo.
Foram realizadas medidas antropométricas de massa corporal (em quilogramas) utilizando uma balança (Filizola, SP, Brasil), estatura (em metros) no estadiômetro (Filizola, SP, Brasil) e de dobras cutâneas: tríceps, subescapular, peitoral, axilar média, bíceps, suprailíaca, abdominal, coxa (terço anterior) e panturrilha, com o plicômetro científico (Lange, Maryland, EUA). O protocolo utilizado para calcular a massa magra e o percentual de gordura foi o de sete dobras cutâneas de Pollock et al. (1984).

Para a realização do teste isocinético foi feita uma adaptação do protocolo utilizado por Goulart et al. (2007) ${ }^{(11)}$. Antes de realizar o teste isocinético, cada sujeito pedalou por 5 min no cicloergômetro (ErgoFit, Ergo Cycle 167, Pirmasens, Alemanha) com carga de 25W e, após o aquecimento, foi posicionado e estabilizado com cintos e velcros no dinamômetro isocinético (Cybex Norm, Cybex International, INC, Ronkonkoma, New York, EUA). A inclinação do encosto da cadeira foi de $85^{\circ}$, o epicôndilo do joelho foi alinhado ao eixo de rotação do dinamômetro e o suporte do braço de alavanca fixado dois dedos acima do maléolo medial da tíbia. A amplitude angular de extensão e flexão do joelho foi de $0^{\circ}$ (extensão total do joelho) a $90^{\circ}$ (flexão).

O joelho referente ao lado dominante (LD) foi testado primeiro e na sequência o do lado não dominante (LND). Os atletas realizaram a familiarização com o equipamento e velocidades avaliadas antes de realizar os testes. O protocolo do teste utilizado está descrito na tabela 1.

Tabela 1. Protocolo do teste realizado pelos atletas.

\begin{tabular}{c|c|c|c|c}
\hline Velocidade & $\begin{array}{c}\text { Grupo } \\
\text { muscular }\end{array}$ & $\begin{array}{c}\text { Tipo de } \\
\text { contração }\end{array}$ & $\begin{array}{c}\text { No de } \\
\text { repetições }\end{array}$ & $\begin{array}{c}\text { Tempo de } \\
\text { descanso final }\end{array}$ \\
\hline $\begin{array}{c}\text { (aquecimento) } \\
\text { Elexores } \\
\text { Extensores }\end{array}$ & Concêntrica & 20 & $45 \mathrm{~s}$ \\
\hline $60 \%$ s (teste) & $\begin{array}{c}\text { Flexores } \\
\text { Extensores }\end{array}$ & Concêntrica & 5 & $50 \mathrm{~s}$ \\
\hline $60 \%$ s (teste) & Flexores & Excêntrica & 5 & $50 \mathrm{~s}$ \\
\hline $300 \%$ s (teste) & $\begin{array}{c}\text { Flexores } \\
\text { Extensores }\end{array}$ & Concêntrica & 30 & $50 \mathrm{~s}$ \\
\hline
\end{tabular}

Durante as contrações máximas, os jogadores receberam incentivos visual (do monitor do computador) e verbal dos avaliadores. Após o teste, eles realizaram alongamento estático dos principais músculos utilizados.

As variáveis coletadas e analisadas no teste foram o PT, as razões convencional e funcional e os déficits bilaterais na velocidade de $60 \% \mathrm{~s}$ e o índice de fadiga na velocidade de $300 \%$ s, sendo que os valores dessas variáveis foram obtidos após correção automática da gravidade e comprimento do segmento. As velocidades de 60\% s e 300\%/s têm sido propostas na literatura ${ }^{(7,11)}$ para a avaliação das razões convencional e funcional, e índice de fadiga, respectivamente.

\section{ANÁLISE ESTATÍSTICA}

Para análise estatística foi utilizado o software SPSS 13.0. Foi realizada a estatística descritiva (média e desvio padrão) para descrever e caracterizar a amostra e o teste de Shapiro-Wilk para medir a normalidade. Para comparação entre as diferentes posições da variável PT do LD e separadamente PT do LND medidas no teste isocinético, foi utilizada Anova de um fator (posição) e post hoc de Bonferroni. Para medir o índice de fadiga entre os flexores e extensores foi utilizada Anova para medidas repetidas (grupo muscular) com um fator (posição). Foi adotado como nível de significância $p \leq 0,05$.

\section{RESULTADOS}

Foram avaliados 27 atletas masculinos com média de idade de 26,55 $\pm 5,1$ sendo seis atacantes $(A)$, sete meias (M) e 14 defesas (D). Os jogadores $M$ apresentaram menor peso corporal $(p<0,05)$ e estatura 
$(p=0,01)$ em comparação aos jogadores $D$. Já a massa magra e o percentual de gordura foram semelhantes para os três grupos, como pode ser observado na tabela 2 .

Tabela 2. Características dos sujeitos por posição (médias e desvio padrão).

\begin{tabular}{c|c|c|c|c}
\hline & Atacante (A) & Meia (M) & Defesa (D) & $\mathbf{p}$ \\
\hline Número & 6 & 7 & 14 & - \\
\hline Idade (anos) & $25,6 \pm 6,7$ & $23,4 \pm 3,5$ & $28,5 \pm 4,4$ & $\mathrm{~ns}$ \\
\hline Massa corporal (kg) & $74,3 \pm 7,4$ & $69,6 \pm 6,0^{\mathrm{a}}$ & $80,0 \pm 8,7$ & 0,04 \\
\hline Estatura (m) & $1,78 \pm 0,05$ & $1,73 \pm 0,04^{\mathrm{b}}$ & $1,81 \pm 0,06$ & 0,01 \\
\hline Massa magra (kg) & $67,2 \pm 4,8$ & $63,1 \pm 3,9$ & $70,9 \pm 7,2$ & $\mathrm{~ns}$ \\
\hline Gordura (\%) & $8,4 \pm 4,7$ & $10,6 \pm 3,5$ & $11,4 \pm 2,8$ & $\mathrm{~ns}$ \\
\hline
\end{tabular}

avalores de massa corporal significativamente inferiores aos do grupo $D(p=0,04)$.

${ }^{b}$ Valores de estatura significativamente inferiores aos do grupo $D(p=0,01)$.

ns = não significativa.

Ao comparar os resultados obtidos nos testes de PT concêntrico de extensores e excêntrico de flexores a $60 \%$, não foram encontradas diferenças significativas entre as posições, tanto para o LD como para o LND. Porém, os D mostraram tendência de terem PT excêntrico de flexores mais elevado que os $M(p=0,06)$ para o LD. Já os resultados obtidos nos testes de PT concêntrico de flexores mostraram diferença significativa entre os atletas das posições $D$ e M, os primeiros apresentaram maiores valores para o LD $(p=0,05)$ (tabela 3 ).

Tabela 3. Valores de média (desvio padrão) dos testes de pico de torque (PT) a $60 \% / \mathrm{s}$ do lado dominante e não dominante separadamente para as diferentes posições.

\begin{tabular}{c|c|c|c|c|c}
\hline PT (Nm) & Lado & Atacante (A) & Meia (M) & Defesa (D) & P \\
\hline Isquiotibiais CON 60\%s & D & $248,8 \pm 32,5$ & $218,0 \pm 48,6^{\mathrm{a}}$ & $259,7 \pm 28,2$ & 0,05 \\
\hline Quadríceps CON 60\%s & D & $379,1 \pm 53,8$ & $353,0 \pm 49,8$ & $403,0 \pm 72,3$ & ns \\
\hline Isquiotibiais EXC 60\% & D & $306,0 \pm 45,1$ & $275,0 \pm 68,1$ & $320,1 \pm 42,1$ & ns \\
\hline Isquiotibiais CON 60\% & ND & $361,3 \pm 58,0$ & $337,4 \pm 36,7$ & $379,2 \pm 74,5$ & ns \\
\hline Quadríceps CON 60\% & ND & $238,6 \pm 36,1$ & $203,1 \pm 41,7$ & $241,8 \pm 27,8$ & ns \\
\hline Isquiotibias EXC 60\% & ND & $271,6 \pm 29,6$ & $244,2 \pm 55,4$ & $297,5 \pm 49,2$ & ns \\
\hline
\end{tabular}

$\mathrm{D}=$ dominante; $\mathrm{ND}$ = não dominante; $\mathrm{ns}$ = não significativa; $\mathrm{CON}$ = concêntrica; $\mathrm{EXC}=$ excêntrica.

a valores de PT concêntrico de isquiotibiais para o lado dominante significativamente inferiores aos valores de PT concêntrico de isquiotibiais para o lado dominante do grupo $D(p=0,05)$.

Todos os grupos encontraram-se dentro dos valores considerados normais de até $15 \%{ }^{(7,9)}$ de déficit bilateral (figura 1). Os três grupos apresentaram maiores valores de PT do LD, observados a partir dos valores positivos resultantes do percentual de DB.

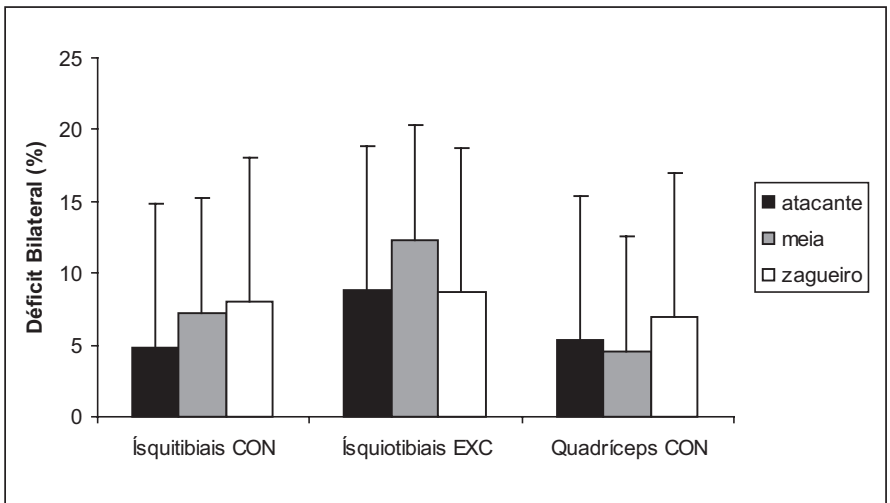

Figura 1. Valores percentuais de déficit bilateral dos grupos atacante (A), meia (M) e defesa (D) nos testes concêntrico (CON) e excêntrico (EXC) para os isquiotibiais e concêntrico para o quadríceps femoral ambos a $60 \%$ s.
Ao analisar o índice de fadiga durante 30 repetições consecutivas, foi possível observar que, independente da função desempenhada e posição ocupada no campo, os atletas apresentam valores semelhantes. Também foi observado que o grupo muscular dos flexores apresentou maior índice de fadiga que os extensores nos atletas M e D para o LD $(p<0,01)$ e tendência do mesmo acontecer para o LND $(p=0,07)$ nos atletas A, M e D. Já para os atletas A, o grupo muscular dos flexores apresentou menor índice de fadiga em comparação aos extensores no LD $(p<0,01)$ (figura 2).

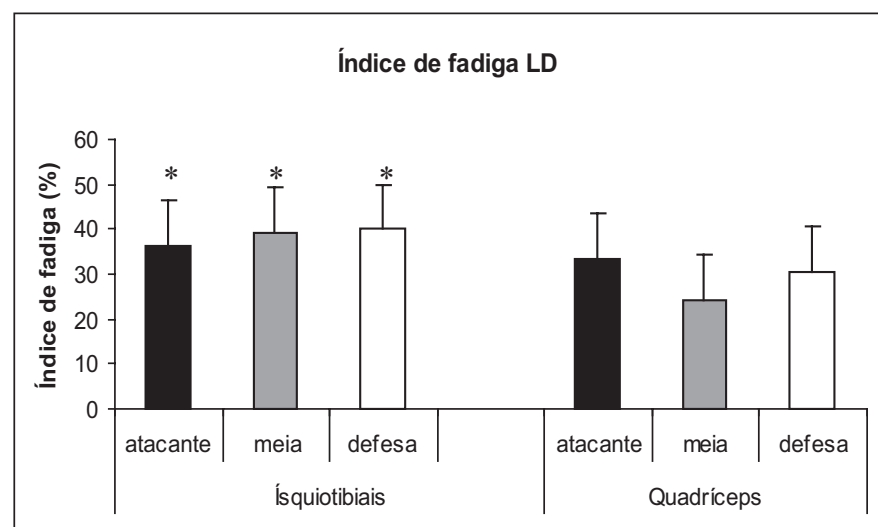

Índice de fadiga LND

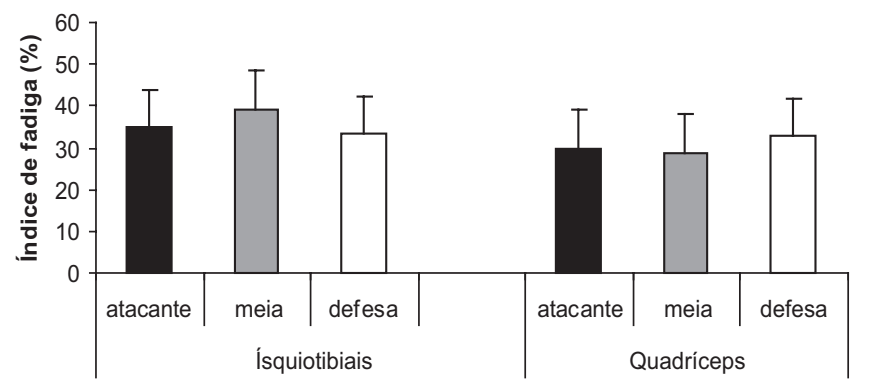

* valores significativamente diferentes $(p<0,01)$ entre $\mathrm{o}$ índice de fadiga dos ísquiotibiais e quadríceps para todos os grupos do lado dominante (LD).

Figura 2. Índice de fadiga dos grupos atacante (A), meia (M) e defesa (D) nos testes concêntrico (CON) para os isquiotibiais e quadríceps femoral ambos a $300 \%$ s separados em lado dominante (LD) e não dominante (LND).

Foram também calculadas a razão convencional $\left(\mathrm{I}_{\text {con }} / \mathrm{Q}_{\text {con }}\right)$ e a razão funcional $\left(I_{\text {exc }} / \mathrm{Q}_{\text {con }}\right)$. Com relação à razão $\mathrm{I}_{\text {con }} / \mathrm{Q}_{\text {con, }}$ todos os grupos encontravam-se dentro dos valores normativos, com médias muito próximas a 0,66 para LD como também para o LND ${ }^{(7,9)}$. Já na razão funcional, todos os valores encontraram-se abaixo da normalidade para jogadores de futebol, que seria igual ou superior a $1^{(3,12,13)}$ (figura 3).

\section{DISCUSSÃO}

O objetivo deste estudo foi o de aplicar testes isocinéticos em jogadores de futebol profissional, comparar os resultados de PT e índice de fadiga obtidos entre as diferentes posições no campo e traçar um perfil desses atletas que atuam no sul do Brasil. Os resultados relativos às medidas antropométricas mostraram diferenças significativas no peso e na estatura entre M e D. Essa diferença também foi encontrada na pesquisa de Tourny-Chollet et al. (2000), e os autores atribuíram esses resultados às diferentes funções desempenhadas pelos jogadores ${ }^{(10)}$. Os defesas, pelo fato de participarem mais efetivamente de jogadas aéreas de interceptação da bola, necessitam apresentar maior estatura, enquanto os meias, que se deslocam mais horizontalmente, não apresentam tal necessidade. 

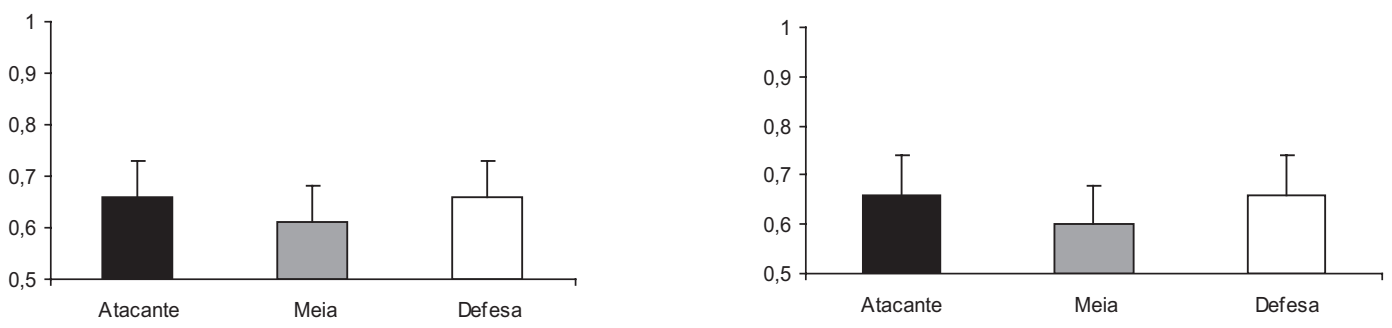

B

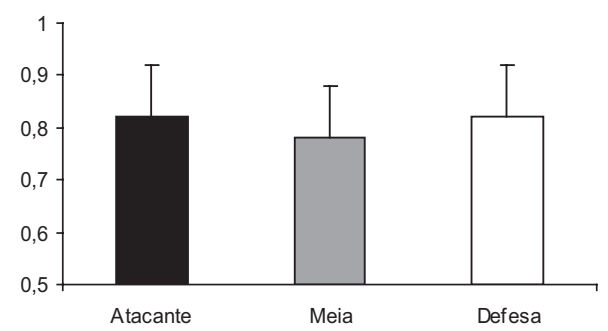

Razão lexc/Qcon ND

D

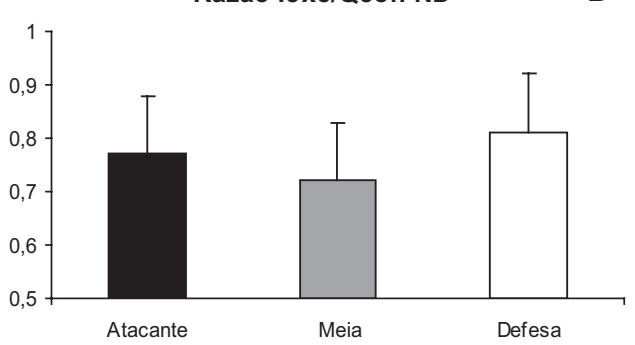

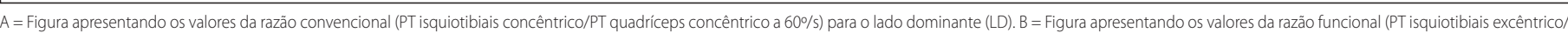

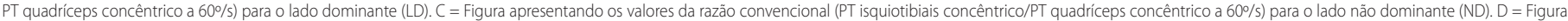
apresentando os valores da razão funcional (PT isquiotibiais excêntrico/PT quadríceps concêntrico a 60\%/s) para o lado não dominante (ND).

Figura 3. Razão convencional ( $\left(_{\text {con }} / Q_{\text {con }}\right)$ e razão funcional $\left(I_{\text {exc }} / Q_{\text {con }}\right)$ dos grupos atacante $(A)$, meia $(M)$ e defesa (D) nos testes concêntricos e excêntrico a $60^{\circ} / s$.

Analisando as médias de PT concêntrico de extensores e PT excêntrico de flexores na velocidade de $60 \%$, não foram encontradas diferenças significativas entre os grupos, porém, uma tendência de o grupo D apresentar maiores valores de PT excêntrico dos flexores no LD em comparação ao M foi observada $(p=0,06)$. Tourny-Chollet et al. (2000), assim como o nosso estudo, não encontraram diferença no PT excêntrico nessa mesma velocidade para diferentes grupos de jogadores, porém, para PT concêntrico dos extensores, dois estudos mostraram valores significativamente maiores para os atacantes em comparação aos jogadores de meio-campo. Ambos os estudos justificaram esta diferença devido ao treino dos atacantes, que é realizado principalmente com movimentos técnicos de sprints curtos, saltos e chutes demandando grande trabalho do quadríceps femoral(2,10). Além dessa diferença, em um dos estudos, foram observados valores superiores de PT do quadríceps nos defesas centrais em comparação às demais posições, com exceção dos goleiros(2). Para os isquiotibiais, o presente estudo encontrou diferenças significativas no PT concêntrico do LD para os grupos D e M $(p=0,05)$, sendo que o grupo $D$ apresentou maiores valores para esta variável. Em um estudo com jogadores portugueses também foram encontradas diferenças de PT concêntrico de flexores, entre goleiros, meias e atacantes e também entre zagueiros e meias, sendo que os goleiros e zagueiros apresentaram sempre maiores valores ${ }^{(2)}$. Essa diferença, apresentada em ambos os estudos, também pode ser explicada devido ao tipo de treinamento principalmente técnico, diferenciado entre os jogadores com funções de defesa, envolvendo maior utilização dos flexores para os movimentos.

Sabe-se que os jogadores de futebol raramente usam ambas as pernas com igual ênfase, e normalmente priorizam o uso do LD para atividades específicas do jogo; desta forma, os programas de treino especializados (técnicos) poderiam desenvolver mais a força de um lado em relação ao outro ${ }^{(3)}$. No estudo de Tourny-Chollet et al. (2000) foi observada maior força concêntrica dos isquiotibiais em velocidade alta (240\%/s) no LD em relação ao $L N D$, porém em velocidades mais baixas nenhuma diferença significativa foi encontrada $a^{(10)}$. No nosso estudo não foram observados déficits bilaterais maiores de $15 \%$ a $60 \%$, ou seja, os atletas se encontravam dentro dos valores de normalidade, porém, o LD apresentou sempre valores iguais ou mais elevados que o LND, visto que o percentual sempre foi positivo. Para Gür et al. (1999) esse maior torque no LD é apresentado pelos jogadores de futebol devido aos anos de treino, visto que atletas mais jovens não mostram esse padrão de diferença bilateral $\left.\right|^{(3,14)}$.

Outros estudos também encontraram resultados semelhantes e relatam que, apesar de algumas habilidades específicas do futebol serem habitualmente realizadas com preferência lateral e o PT deste ser maior, os resultados do teste isocinético sugerem que, independentemente da função desempenhada, os atletas avaliados são funcionalmente equilibrados bilateralmente ${ }^{(2,3,8)}$. Magalhães et al. (2001) justificam esse equilíbrio pela participação ativa e diferenciada quanto ao modo contrátil do membro LND nas ações de passe e chute como perna de apoio ${ }^{(8)}$.

$\mathrm{O}$ índice de fadiga indica a habilidade do indivíduo de realizar o mesmo movimento repetidas vezes com determinada resistência. Na avaliação isocinética, ele é analisado levando em consideração a diferença do torque entre as primeiras e as últimas repetições realizadas durante o teste. No teste de fadiga, para os grupos M e D, observou-se maior percentual de queda de PT dos isquiotibiais em comparação ao quadríceps para o LD ( $p<0,01)$. Sangnier e Tourny-Chollet (2008) também avaliaram jogadores de futebol e observaram que essa queda de torque ocorre de forma linear tanto para os flexores quanto para os extensores de joelho(15). Em outro estudo recente, os mesmos autores mostraram que, durante o teste isocinético de fadiga, a resistência à fadiga diverge entre o quadríceps femoral e os isquiotibiais, sendo que, os flexores reduzem mais o torque em comparação aos extensores ${ }^{(16)}$, resultados estes que estão de acordo com os do nosso estudo. Essa maior diminuição de PT dos isquiotibiais pode ser atribuída a características estruturais e metabólicas dos mesmos, visto que há maior proporção de fibras do tipo Il nestes músculos em relação ao quadríceps ${ }^{(17)}$. Como as fibras do tipo II fadigam mais rapidamente ${ }^{(18)}$, os isquiotibiais apresentam maior diminuição de PT ao longo do tempo. Sendo assim, pode-se especular que pelo fato dos músculos isquiotibiais apresentarem maior número de fibras rápidas e também por serem mais susceptíveis à fadiga, os jogadores M e D apresentaram percentual de queda maior de PT dos flexores. Curiosamente, o comportamento do grupo A para LD foi contrário, apresentando menor índice de fadiga para os 
flexores em comparação aos extensores $(p<0,01)$. Sendo assim, sugerese que esses atletas tiveram maior treino específico desta musculatura em comparação aos demais.

Devido a essa queda diferenciada de PT entre isquiotibiais e quadríceps, causada pela fadiga, evidencia-se uma tendência ao desequilíbrio muscular. Essas condições podem afetar a estabilidade articular e predispor a articulação do joelho às lesões. Dessa forma, sugere-se que a razão convencional para atletas fique acima da média de 0,66, já que durante a partida, devido às condições de fadiga progressiva, ela poderá decair, aumentando o risco de lesão muscular.

A razão convencional é obtida pela divisão do PT concêntrico dos isquiotibiais pelo PT concêntrico do quadríceps femoral. Parece já haver um consenso estabelecido entre vários autores de que o valor normativo para essa razão para jogadores de futebol é de 0,66 para velocidades baixas como de $60^{\circ} / s^{(4,12,13)}$. No presente estudo, todos os atletas avaliados encontravam-se dentro do intervalo considerado normal, segundo Dvir $(2004)^{(7)}$. Os resultados encontrados foram mais elevados em comparação à pesquisa de Magalhães et al. (2001), em que as razões dos atletas de futebol ficaram na faixa de $51 \%$ a $57 \%{ }^{(8)}$. Ainda que a razão convencional tenha sido considerada importante até hoje, há indícios que a sua análise isolada é insuficiente para a avaliação da estabilidade articular do joelho. Atualmente, parece que a associação das razões convencional e funcional está se mostrando mais efetiva neste aspecto ${ }^{(12,13)}$.

A razão funcional é obtida pela divisão do PT excêntrico dos isquiotibiais pelo PT concêntrico do quadríceps. Com a evolução dos estudos, foi observado que durante a extensão do joelho, como no caso do chute no futebol, a contração dinâmica concêntrica do quadríceps femoral está associada a um movimento de translação anterior da tíbia, sobretudo quando o movimento é realizado em altas velocidades e em extensão completa( ${ }^{(4,12,13,19)}$. Além disso, também acontece a rotação interna da tíbia em relação ao fêmur causando forte estresse no ligamento cruzado anterior (LCA). Para diminuir esses efeitos da extensão do joelho, os isquiotibiais devem contrair-se excentricamente ajudando a frear o movimento e reduzir o deslizamento e rotação interna da tíbia(4,12). Quando há equilíbrio na razão funcional, ou seja, seu valor estiver em torno de 1, isso indica significante capacidade dos isquiotibiais promoverem a estabilização articular do joelho ${ }^{(12,13)}$. Desta maneira, o LCA não sofreria um incremento da sobrecarga de tensão durante a extensão do joelho e se encontraria com baixo risco de lesão.

O valor de razão funcional sugerido para equilíbrio muscular acima descrito é em torno de 1, porém, evidencia-se que durante a partida de futebol ocorre fadiga muscular e o PT excêntrico dos isquiotibiais decai, principalmente, no final do primeiro tempo e final da partida, consequentemente diminuindo a razão $\mathrm{I}_{\text {exc }} / \mathrm{Q}_{\text {con }}{ }^{(5,6)}$. Desta forma, é importante

\section{REFERÊNCIAS}

1. Cometti G, Maffiuletti NA, Pousson M, et al. Isokinetic Strength and Anaerobic Power of Elite, Subelite and Amateur French Soccer Players. Int I Sports Med 2001;22:45-51.

2. Carvalho P, Cabri J. Avaliação isocinética da força dos músculos da coxa dos futebolistas. Revista Portuguesa de Fisioterapia no Desporto 2007;1:4-12

3. Iga J, George K, Lees A, Reilly T. Cross-sectional investigation of indices of isokinetic leg strength in youth soccer players and untrained individuals. Scand J Med Sci Sports 2008;1-6.

4. Crosier JL, Gateau S, Bitnet J, Gently M, Ferret JM. Strength imbalances and prevention of hamstring injury in Professional soccer players: A prospective study. Am J Sports Med 2008;36:1469-75.

5. Small K, McNaughton L, Greig M, Lovell R. The effects of multidirectional soccer-specific fatigue on markers of hamstring injury risk. J Sci Med Sport (2008).

6. Greig M. The Influence of Soccer-Specific Fatigue on Peak Isokinetic Torque Production of the Knee Flexors and Extensors. Am J Sports Med 2008;36:1403-9.

7. Dvir Z. Isocinética: Avaliaçōes Musculares, Interpretações e Aplicações Clínicas 1ª Ed. Manole, São Paulo, 2002

8. Magalhães J, Oliveira J, Ascensão A, Soares JMC. Avaliação isocinética da força muscular de atletas em função do desporto praticado, idade, sexo e posiçōes específicas. Revista Portuguesa de Ciências do Desporto 2001;1:13-21

9. Brown Lee. Isokinetics in Human Performance. 1a Ed. Human Kinetics Profe, 2000.

10. Tourny-Chollet C, Leroy D, Léger H, Beuret-Blanquart F. Isokinetic knee muscle strength of soccer players according to their position. Isokinet Exerc Sci 2000;8:187-93.

11. Goulart LF, Dias RMR, Altimari LR. Força isocinética de jogadores de futebol categoria sub-20: comparação entre diferentes posições de jogo. Revista Brasileira de Cineantropometria \& Desempenho Humano 2007;9:165-9. que o atleta, apresente valores acima de 1, já que durante o jogo estes tendem a diminuir, tornando o atleta susceptível à lesão. Os resultados das avaliações de razão funcional observados neste estudo estão abaixo da normalidade, o que sugere elevada predisposição a lesões dos sujeitos avaliados, fato inconcebível por se tratar de atletas profissionais.

Ainda que relativamente à razão convencional os atletas avaliados no presente estudo encontravam-se dentro dos limites normais apresentados na literatura, o mesmo não pode ser referido quanto aos valores da razão funcional considerados. Tal fato salienta que somente a avaliação $\mathrm{I}_{\text {con }} / \mathrm{Q}_{\text {con }}$ não é suficiente para a determinação da estabilidade da articulação do joelho e do risco de exposição à lesão, sendo mais prudente considerar simultaneamente as razões convencional e funcional.

\section{CONCLUSÃO}

Ao analisar os resultados do presente estudo, foi observado que não há diferenças significativas de PT concêntrico do quadríceps e PT excêntrico dos isquiotibiais tanto do LD como do LND entre os jogadores de futebol que atuam nas posições $A, M$ e D. Porém, os D apresentam valores maiores de PT concêntrico dos flexores em relação aos $M$ para o LD $(p=0,05)$ e tendência do mesmo ocorrer para PT excêntrico dos flexores no LD $(p=0,06)$. Desta forma, nota-se diferença entre jogadores de defesa e meio-campo. Isso pode ter ocorrido devido às funções diferenciadas que estes atletas possuem dentro de campo, que requerem movimentos diferentes e inúmeras repetições que podem levá-los a um determinado perfil muscular.

Além disso, não foram encontradas diferenças entre todos os grupos quanto ao índice de fadiga, assim como todos os atletas apresentavam valores normativos de déficit bilateral. Sendo assim, apesar de desempenharem funções diferentes dentro do campo, isso não parece influenciar a maioria das características neuromusculares nos membros inferiores dos atletas de futebol avaliados.

Com relação às razões, os jogadores encontravam-se dentro dos valores normativos para a razão convencional, porém, estavam abaixo dos valores normais para a razão funcional. Pelo fato de a razão funcional abaixo dos valores de referência estar fortemente associada à incidência de lesões musculoarticulares, seria conveniente que os profissionais atuantes no treino dos jogadores dessem mais ênfase ao treino de força, principalmente excêntrico dos músculos isquiotibiais, e que buscassem avaliar os seus atletas regularmente com o objetivo de reduzir a exposição desses atletas às lesões frequentemente associadas à prática do futebol em nível profissional, sobretudo àquelas decorrentes do desequilíbrio de forças dos músculos flexores e extensores da articulação do joelho.

Todos os autores declararam não haver qualquer potencial conflito de interesses referente a este artigo.

12. Aagaard P, Simonsen EB, Magnusson SP, Larsson B, Dyhre-Poulsen P. A New Concept for Isokinetic Hamstring: Quadriceps Muscle Strength Ratio. Am J Sports Med 1998;26:231.

13. Coombs R, Garbutt G. Developments in the use of the hamstring/quadriceps ratio for the assessment of muscle balance. JSSM 2002;1:56-62.

14. Gür H, Akova B, Pündük Z, Küçükoğlu S. Effects of age on the reciprocal peak torque ratios during knee muscle contractions in elite soccer players. Scand J Med Sci Sports 1999;9:81-7.

15. Sangnier S, Tourny-Chollet C. Study of the fatigue curve in quadriceps and hamstrings of soccer layers during isokinetic endurance testing. J Strength Cond Res 2008;22:1458-67.

16. Sangnier S, Tourny-Chollet C. Effect of fatigue on hamstrings and quadriceps during isokinetic fatigue testing in semiprofessional soccer players. Int J Sport Med 2007;28:952-7.

16. Garrett WE Jr, Califf JC, Bassett FH. Histochemical correlates of hamstring injuries. Am J Sports Med 1984;12:98-103.

17. Maughan R, Gleeson M, Greenhaff PL. Bioquímica do Exercício e do Treinamento 1ª ed. Brasileira. Ed. Manole, São Paulo, 2000.pg 146.

18. Aagaard P, Simonsen EB, Andersen JL, Magnusson SP, Bojsen-Moller F, Dyhre-Poulsen P. Antagonist muscle coactivation during isokinetic knee extension. Scand J Med Sci Sports 2000;10:58-67.

19. Woods C, Hawking RD, Maltby S, Hulse M, Thomas A, Hodson A. The Football Association Medical Research Programme: an audit of injuries in professional football-analysis of hamstring injuries. Br J Sports Med 2004;38:36-41.

20. Le Gall F, Carling C, Reilly T, Vandewalle H, Church J, Rochconger P. Incidence of injuries in elite French youth soccer players: a10-season study. Am J Sports Med 2006:34:928-38. 